Article

\title{
Imidazoles-Intercalated $\alpha$-Zirconium Phosphate as Latent Thermal Initiators in the Reaction of Glycidyl Phenyl Ether (GPE) and Hexahydro-4-Methylphthalic Anhydride (MHHPA)
}

\author{
Osamu Shimomura ${ }^{1, *}$, Kensuke Tokizane ${ }^{1}$, Takatoshi Nishisako ${ }^{1}$, Shunro Yamaguchi ${ }^{2, *}$, \\ Junko Ichihara $^{2}$, Manabu Kirino ${ }^{3}$, Atsushi Ohtaka ${ }^{1}$ and Ryôki Nomura ${ }^{1}$ \\ 1 Department of Applied Chemistry, Osaka Institute of Technology, 5-16-1 Omiya, Ashahi-ku, \\ Osaka 535-8585, Japan; konnkonnkitune127@yahoo.co.jp (K.T.); nt2435@icloud.com (T.N.); \\ atsushi.otaka@oit.ac.jp (A.O.); ryoki.nomura@oit.ac.jp (R.N.) \\ 2 Institute of Scientific and Industrial Research, Osaka University, 8-1 Mihogaoka, Ibaraki, \\ Osaka 567-0047, Japan; ichihara@sanken.osaka-u.ac.jp \\ 3 R \& D Group, ThreeBond Co., Ltd., 1-1 Oyama-cho, Midori-ku, Sagamihara, Kanagawa 252-0416, Japan; \\ m-kirino@threebond.co.jp \\ * Correspondence: osamu.shimomura@oit.ac.jp (O.S.); shunro@sanken.osaka-u.ac.jp (S.Y.); \\ Tel.: +81-6-6954-4269 (O.S.); +81-6-6879-8473 (S.Y.)
}

Academic Editor: Monica Pica

Received: 16 February 2017; Accepted: 19 May 2017; Published: 1 June 2017

\begin{abstract}
The capabilities of imidazoles-intercalated $\alpha$-zirconium phosphate ( $\alpha$-ZrP·imidazole): imidazol ( $\alpha$-ZrP·Im), 2-methylimidazole ( $\alpha$-ZrP·2MIm), and 2-ethyl-4-methylimidazole ( $\alpha$-ZrP·2E4MIm) as latent thermal initiators were examined by the copolymerization of glycidyl phenyl ether (GPE) and hexahydro-4-methylphthalic anhydride (MHHPA) with the imidazoles-intercalated $\alpha$-zirconium phosphate at varying temperatures for one-hour periods. Polymerization was not observed until the reactants were heated to $100{ }^{\circ} \mathrm{C}$ or above. Increasing the temperature, polymerization in the presence of $\alpha$-ZrP.Im, $\alpha$-ZrP.2MIm, or $\alpha$-ZrP.2E4MIm proceeded at $140{ }^{\circ} \mathrm{C}$ for $1 \mathrm{~h}$ with over $90 \%$ conversion. The thermal stabilities of $\alpha$-ZrP.Im, $\alpha$-ZrP.2MIm, and $\alpha$-ZrP.2E4MIm in the reaction at $40{ }^{\circ} \mathrm{C}$ for $264 \mathrm{~h}$ were tested. With $\alpha-\mathrm{ZrP} \cdot 2 \mathrm{MIm}$, the conversion was less than $15 \%$ up to $96 \mathrm{~h}$. In the cases of $\alpha$-ZrP.Im and $\alpha$-ZrP.2E4MIm, the conversion reached less than $15 \%$ at $264 \mathrm{~h}$. The thermal stabilities of $\alpha$-ZrP.Im, $\alpha$-ZrP.2MIm, and $\alpha-\mathrm{ZrP} \cdot 2 \mathrm{E} 4 \mathrm{MIm}$ at $40{ }^{\circ} \mathrm{C}$ were superior to those of the commercially available thermal latent initiators: HX-3088 and HX-3722.
\end{abstract}

Keywords: latent thermal initiator; intercalation; $\alpha$-zirconium phosphate; imidazole; glycidyl phenyl ether

\section{Introduction}

There has been considerable interest in the development of latent polymerization catalysts that are inert in the monomer or prepolymer under storage conditions. These catalysts can initiate polymerization under external impetus such as thermal or photo irradiation. Various kinds of latent catalysts are used in the polymerization reaction such as sulfonium salt [1-4], phosphonium salt [5], pyrazinium salt [6], $N$-heterocyclic carbene [7], aminimide [8], and sulfonate [9]. We have previously reported that primary alkylamines intercalated with $\alpha$-zirconium phosphate $(\alpha-\mathrm{ZrP})$ can serve as latent thermal initiators in the reaction of glycidyl phenyl ether (GPE) [10] and that intercalation compounds of 1,4-diazabicyclo(2,2,2)octane (DABCO) and 1,8-diazabicyclo(5,4,0)undec-7-ene (DBU) with $\alpha$-ZrP: 
$\alpha-\mathrm{ZrP} \cdot \mathrm{DABCO}$ and $\alpha-\mathrm{ZrP}$.DBU show good performance as latent thermal catalysts in the reaction of GPE with hexahydro-4-methylphthalic anhydride (MHHPA) [11].

Aside from DBU and DABCO, imidazoles have been widely used for curing epoxy resins as cured epoxy resins give good thermal resistance and physical properties because of the reactivity in chain polymerization with epoxide [12,13]. Latent thermal initiators of imidazoles have been developed. Romanchick prepared 1,3-dialkylimidazolium salts in the curing of epoxy resin [14]. In this case, the activation of catalyst needs a high temperature around $200{ }^{\circ} \mathrm{C}$. Shin reported using microencapsulated imidazoles with polycaprolactone [15]. Arimitsu et al. proposed using the Michel addition products of imidazoles and fumarate ester to improve the low miscibility in epoxy resin [16]. However, these catalysts remain the blocking residues following the reaction to epoxy groups. These residues might be attributed to the deterioration of the resin. Amine-intercalated $\alpha$ - $\mathrm{ZrP}$ can act as latent thermal initiators $[17,18]$ and the blocking residues of $\alpha-\mathrm{ZrP}$ can act as additives for reinforcement of resins [19-21].

A series of imidazoles are expected to have different $\mathrm{p} K_{\mathrm{a}}$ due to their substituents and to have different reactivity as the intercalation compounds of $\alpha$-ZrP. We prepared intercalation compounds of imidazole (Im), 2-methylimidazole (2MIm), and 2-ethyl-4-methylimidazole (2E4MIm) with $\alpha$-ZrP (hereafter abbreviated as $\alpha$-ZrP.Im, $\alpha$-ZrP.2MIm, and $\alpha$-ZrP.2E4MIm) and examined the capabilities of $\alpha$-ZrP.Im, $\alpha$-ZrP.2MIm, and $\alpha$-ZrP.2E4MIm as latent thermal initiators in the curing of GPE with hexahydro-4-methylphthalic anhydride (MHHPA). The $\mathrm{p} K_{\mathrm{a}}$ value of $\mathrm{Im}, 2 \mathrm{MIm}$, and 2E4MIm were 6.99 [22], 7.75 [22], and 8.3 [23], respectively. Latent thermal initiators containing imidazoles have been developed and the polymer-encapsulated imidazoles HX-3088 and HX-3722 are now commercially available. For comparison, the commercially available latent thermal initiators HX-3088 and HX-3722 were tested in the polymerization of GPE with MHHPA.

\section{Results and Discussion}

The intercalation compounds were prepared by mixing imidazole ( $\mathrm{Im}), 2$-methylimidazole (2MIm), or 2-ethyl-4-methylimidazole (2E4MIm) with $\alpha-\mathrm{ZrP}$ by a similar procedure of another reported method [24]. The compositions determined by elemental analyses were $\mathrm{Zr}\left(\mathrm{HPO}_{4}\right)_{2}\left(\mathrm{C}_{3} \mathrm{H}_{4} \mathrm{~N}_{2}\right)_{0.78} \cdot 1 \cdot 1 \mathrm{H}_{2} \mathrm{O}$ $(\alpha-\mathrm{ZrP} \cdot \mathrm{Im}), \mathrm{Zr}\left(\mathrm{HPO}_{4}\right)_{2}\left(\mathrm{C}_{4} \mathrm{H}_{6} \mathrm{~N}_{2}\right)_{0.96} \cdot 1.2 \mathrm{H}_{2} \mathrm{O}(\alpha-\mathrm{ZrP} \cdot 2 \mathrm{MIm})$, and $\mathrm{Zr}\left(\mathrm{HPO}_{4}\right)_{2}\left(\mathrm{C}_{6} \mathrm{H}_{10} \mathrm{~N}_{2}\right)_{0.65} \cdot 0.6 \mathrm{H}_{2} \mathrm{O}$ $(\alpha-\mathrm{ZrP} \cdot 2 \mathrm{E} 4 \mathrm{MIm})$, respectively. Assuming that the weight loss after the weight loss of water was attributed to that of imidazoles, each of the compositional formula was calculated; $\alpha$-ZrP.Im: $\mathrm{Zr}\left(\mathrm{HPO}_{4}\right)_{2}\left(\mathrm{C}_{3} \mathrm{H}_{4} \mathrm{~N}_{2}\right)_{0.87} \cdot 0.92 \mathrm{H}_{2} \mathrm{O}, \alpha-\mathrm{ZrP} \cdot 2 \mathrm{MIm}: \mathrm{Zr}\left(\mathrm{HPO}_{4}\right)_{2}\left(\mathrm{C}_{4} \mathrm{H}_{6} \mathrm{~N}_{2}\right)_{0.94} \cdot 1.5 \mathrm{H}_{2} \mathrm{O}$, and $\alpha-\mathrm{ZrP} \cdot 2 \mathrm{E} 4 \mathrm{MIm}$, $\mathrm{Zr}\left(\mathrm{HPO}_{4}\right)_{2}\left(\mathrm{C}_{6} \mathrm{H}_{10} \mathrm{~N}_{2}\right)_{0.72} \cdot 0.13 \mathrm{H}_{2} \mathrm{O}$. The basal distances of $10.7 \AA\left(2 \theta=8.2^{\circ}\right)$ for $\alpha$-ZrP.Im, $12.1 \AA$ $\left(2 \theta=7.3^{\circ}\right)$ for $\alpha$-ZrP.2MIm and $12.9 \AA\left(2 \theta=6.9^{\circ}\right)$ for $\alpha$-ZrP.2E4MIm expanded compared with that of pristine $\alpha-\operatorname{ZrP}\left(7.6 \AA, 2 \theta=11.7^{\circ}\right)$. The thermal properties of these $\alpha$-ZrP-imidazoles intercalation compounds were examined by thermogravimetric analysis (TGA) shown in Figure 1 . The thermal weight loss around $100{ }^{\circ} \mathrm{C}$ showed a decrease of water. After the weight loss of water, $\alpha$-ZrP.Im was stable up to $250{ }^{\circ} \mathrm{C}$ and weight decreased until $600{ }^{\circ} \mathrm{C}$. In $\alpha$-ZrP.2MIm and $\alpha$-ZrP.2E4MIm, the weights gradually decreased from $175^{\circ} \mathrm{C}$ until $600{ }^{\circ} \mathrm{C}$. Up to $140{ }^{\circ} \mathrm{C}$ of the curing temperature (discussed later), these $\alpha$-ZrP-imidazoles intercalation compounds thermally lost $\mathrm{H}_{2} \mathrm{O}$ rather than the imidazoles. Polymerization of GPE with MHHPA in the presence of $\alpha$-ZrP.Im, $\alpha$-ZrP.2MIm, and $\alpha$-ZrP.2E4MIm containing $3 \mathrm{~mol} \%$ of each intercalation compound for GPE at $140{ }^{\circ} \mathrm{C}$ was performed to produce poly(GPE-co-MHHPA) as shown in Scheme 1. The molecular weights and the molecular weight distribution of the resulting poly(GPE-co-MHHPA) were determined by GPC: $M n=2000$, $M w / M n=1.4$ for $\alpha-\mathrm{ZrP} \cdot \operatorname{Im}$ at $140{ }^{\circ} \mathrm{C}$ for $2 \mathrm{~h}, \mathrm{Mn}=2100, M w / M n=1.4$ for $\alpha-\mathrm{ZrP} \cdot 2 \mathrm{MIm}$ at $140{ }^{\circ} \mathrm{C}$ for $1 \mathrm{~h}$, and $M n=3100, M w / M n=1.3$ for $\alpha-\mathrm{ZrP} \cdot 2 \mathrm{E} 4 \mathrm{MIm}$ at $140^{\circ} \mathrm{C}$ for $1 \mathrm{~h}$, respectively. The conversion of GPE for $\alpha$-ZrP.Im was $72 \%$ at $140{ }^{\circ} \mathrm{C}$ for $1 \mathrm{~h}$, the reaction time was extended to $2 \mathrm{~h}$ to obtain the quantitative conversion. The molecular weight and molecular weight distribution of poly(GPE-co-MHHPA) were previously reported as $M n=2600, M w / M n=1.4$ for $\alpha-Z r P \cdot D A B C O$, and $M n=720$ and $M w / M n=1.2$ for $\alpha$-ZrP·DBU [11]. 


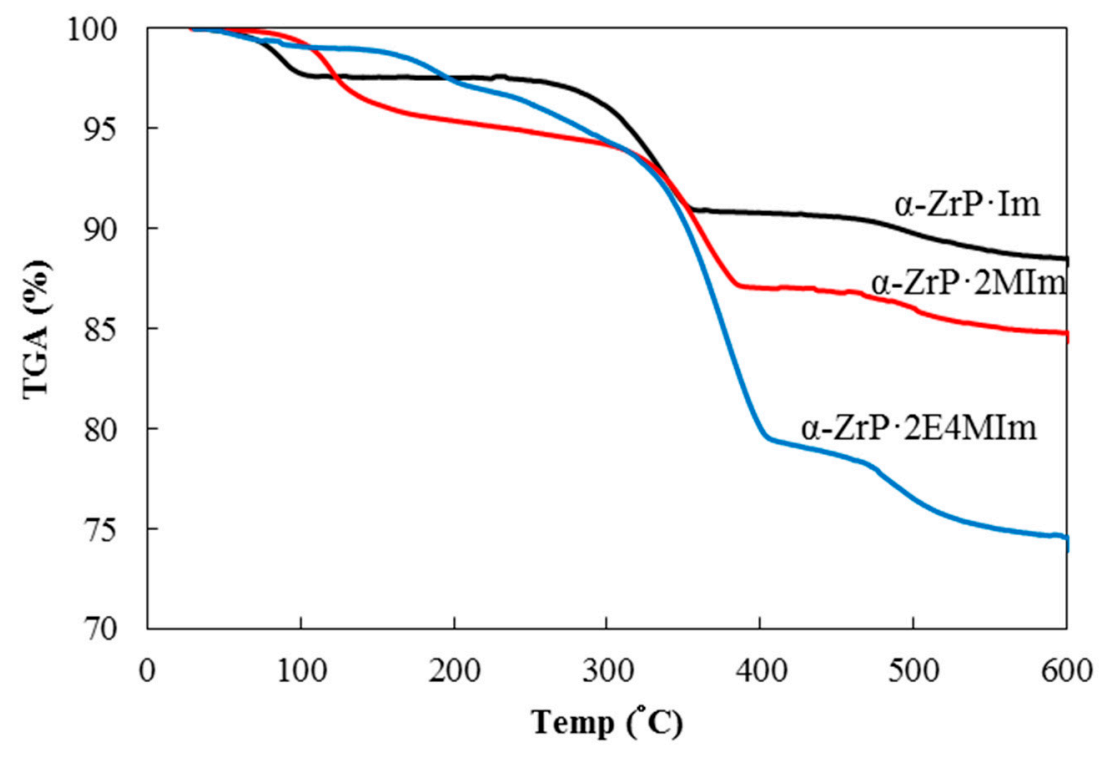

Figure 1. TGA curves of $\alpha-\mathrm{ZrP} \cdot \operatorname{Im}(-), \alpha-\mathrm{ZrP} \cdot 2 \mathrm{MIm}(-)$, and $\alpha-\mathrm{ZrP} \cdot 2 \mathrm{E} 4 \mathrm{MIm}(-)$.
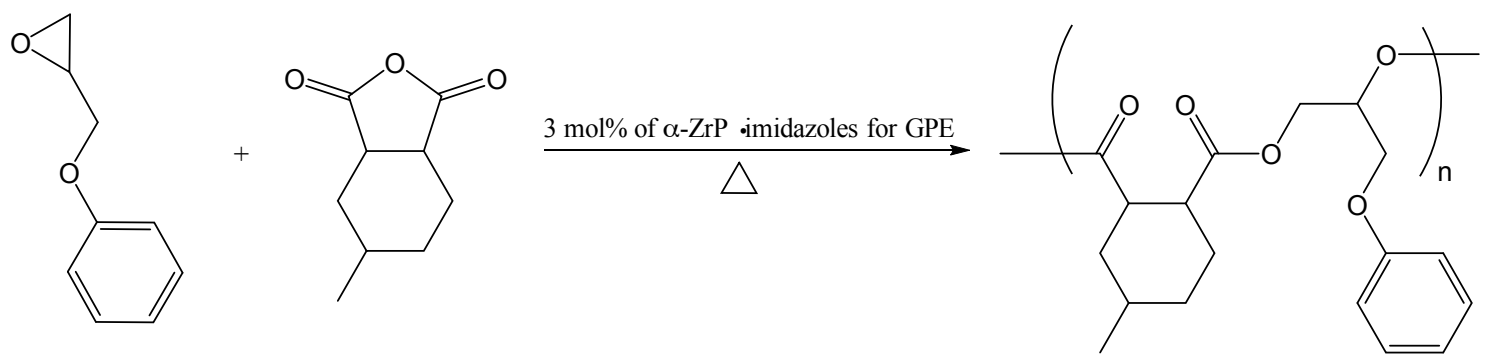

Scheme 1. Synthesis of poly(GPE-co-MHHPA).

The capabilities of the $\alpha-\mathrm{ZrP} \cdot \mathrm{Im}, \alpha-\mathrm{ZrP} \cdot 2 \mathrm{MIm}$, and $\alpha$-ZrP·2E4MIm as latent initiators were examined in the reactions of GPE with MHHPA containing $3 \mathrm{~mol} \%$ of each intercalation compound for GPE at varying temperatures for $1 \mathrm{~h}$ periods by ${ }^{1} \mathrm{H}-\mathrm{NMR}$ technique as shown in Figure 2. The conversions of GPEs were measured from the area ratio of the aromatic protons at $\delta 6.9$ and the methylene protons of $\delta 2.92$ (indicated by arrows), which relatively decreased with an increase in the reaction temperature from 80 to $140{ }^{\circ} \mathrm{C}$ (Figure 2).

Figure 3 shows the conversions of GPE in the reaction with $\alpha$-ZrP.Im, $\alpha-\mathrm{ZrP} \cdot 2 \mathrm{MIm}$, or $\alpha$-ZrP.2E4MIm at these temperatures over a $1 \mathrm{~h}$ period. In each case, GPE did not substantially change below $80{ }^{\circ} \mathrm{C}$. Particularly in the case of $\alpha$-ZrP.Im, the reaction did not proceed at $100{ }^{\circ} \mathrm{C}$. With an increase in temperature, the reactions with any $\alpha-Z r P$ intercalation compound gradually proceeded and reached over $94 \%$ of conversions at $140{ }^{\circ} \mathrm{C}$. These $\alpha$-ZrP intercalation compounds were thermally stable and required $140{ }^{\circ} \mathrm{C}$ of curing temperature as initiators. Commercially available latent thermal curing agents such as the microencapsulated imidazoles of HX-3088 and HX-3722 also did not effectively initiate the reaction up to $80^{\circ} \mathrm{C}$. When the temperature was increased, the reaction fairly proceeded at $100{ }^{\circ} \mathrm{C}$ with $66 \%$ conversion for HX-3088 and 75\% conversion for HX-3722. However, these initiators required $140{ }^{\circ} \mathrm{C}$ of curing temperature as well as the imidazoles-intercalated $\alpha-\mathrm{ZrP}$. Arimitsu et al. reported that the imidazole derivatives prepared from fumarate ester as latent thermal initiators of butyl glycidyl ether. The reaction completely proceeded at $150{ }^{\circ} \mathrm{C}$ for $30 \mathrm{~min}$ [16]. 


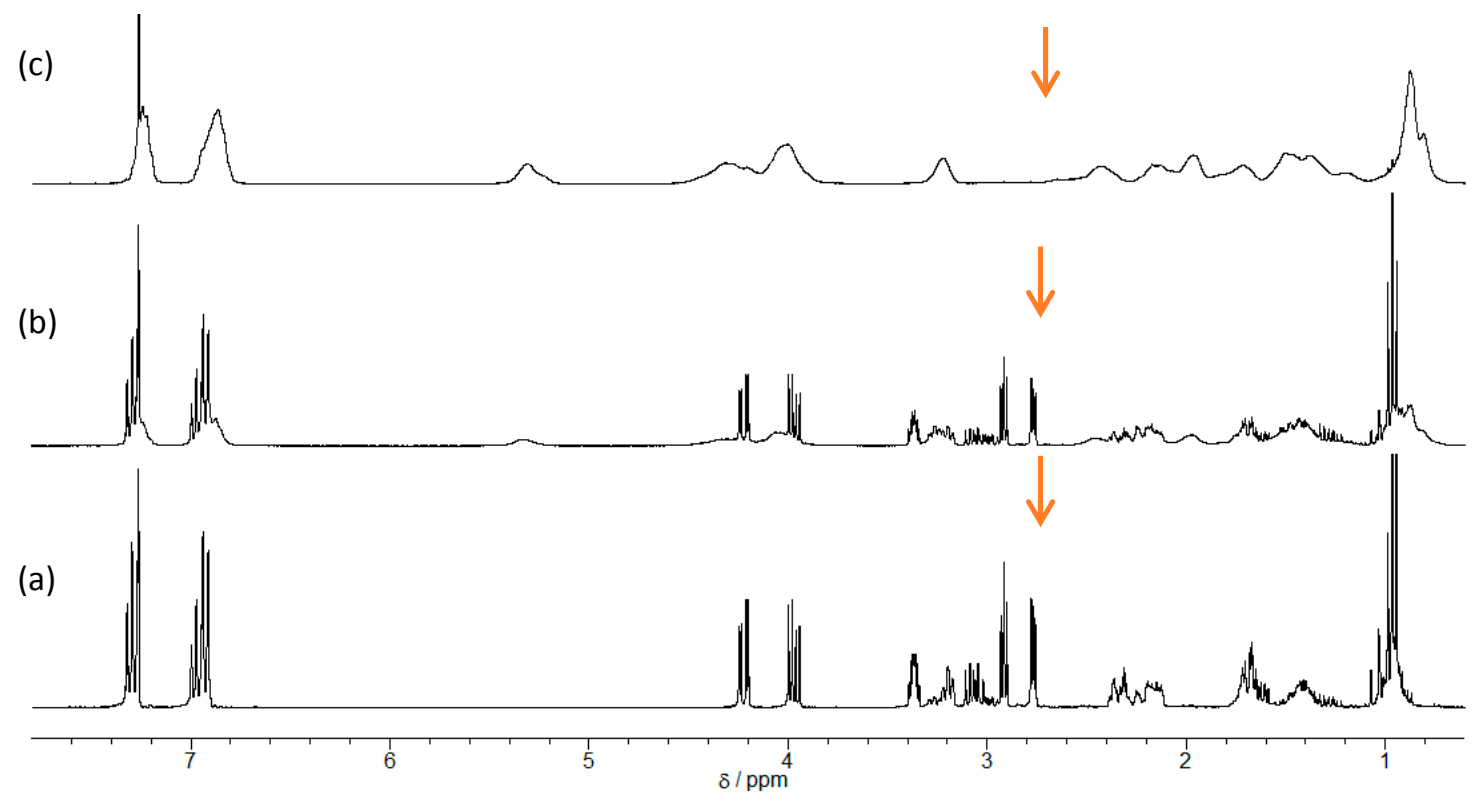

Figure 2. The ${ }^{1} \mathrm{H}-\mathrm{NMR}$ spectra of GPE-MHHPA (glycidyl phenyl ether- hexahydro-4-methylphthalic anhydride) with $\alpha$-ZrP.Im at (a) $80^{\circ} \mathrm{C}$, (b) $120^{\circ} \mathrm{C}$, and (c) $140{ }^{\circ} \mathrm{C}$ for $1 \mathrm{~h}$.

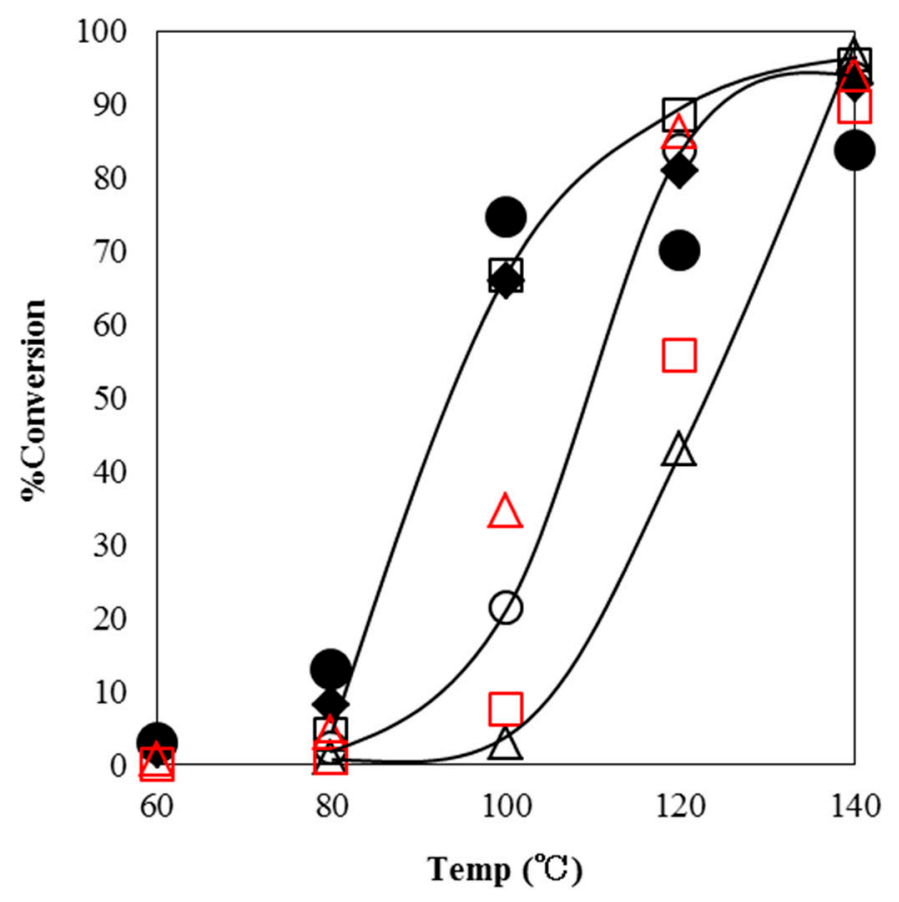

Figure 3. The conversion of GPE after $1 \mathrm{~h}$ as a function of temperature during polymerization with $\alpha$-ZrP·Im (- $\Delta-), \alpha-Z r P \cdot 2 M I m(-\square-), \alpha-Z r P \cdot 2 E 4 M I m(-\odot-), \alpha-Z r P \cdot D A B C O ~(\square) ~[11], \alpha-Z r P \cdot D B U(\Delta)[11]$, HX-3088 $(\diamond)$, and HX-3722 $(\bullet)$.

The thermal stabilities of $\alpha$-ZrP·Im, $\alpha$-ZrP·2MIm, $\alpha$-ZrP·2E4MIm, HX-3088, and HX-3722 were tested with the following conversion of GPE at $40{ }^{\circ} \mathrm{C}$ as shown in Figure 4 . With $\alpha-\mathrm{ZrP} \cdot 2 \mathrm{MIm}$, the conversion was less than $15 \%$ up to $96 \mathrm{~h}$. In the cases of $\alpha-\mathrm{ZrP} \cdot \operatorname{Im}$ and $\alpha-\mathrm{ZrP} \cdot 2 \mathrm{E} 4 \mathrm{MIm}$, the conversion reached less than $15 \%$ at $264 \mathrm{~h}$. The thermal stabilities of $\alpha-\mathrm{ZrP} \cdot \mathrm{Im}, \alpha-\mathrm{ZrP} \cdot 2 \mathrm{MIm}$, and $\alpha-\mathrm{ZrP} \cdot 2 \mathrm{E} 4 \mathrm{MIm}$ were superior to those of HX-3088 and HX-3722. 


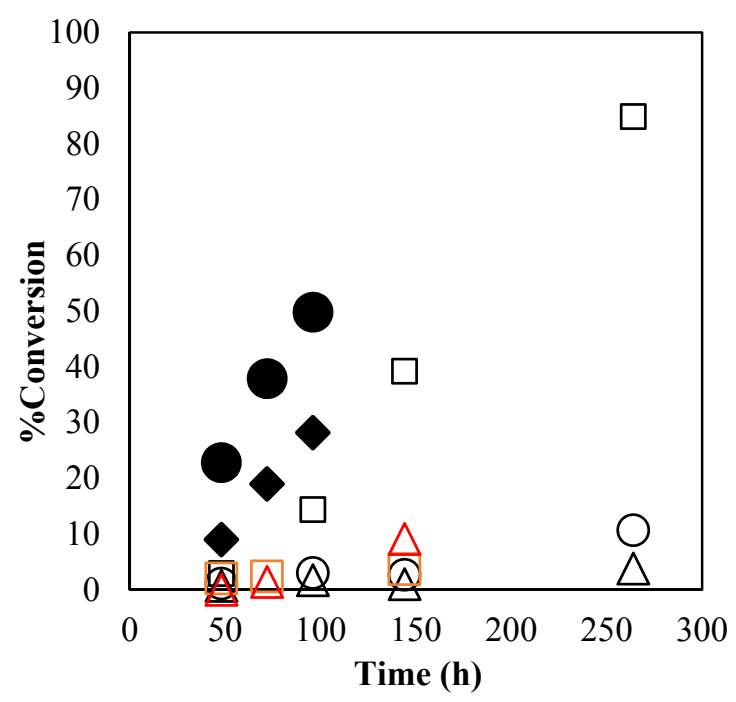

Figure 4. The conversion of GPE after $1 \mathrm{~h}$ as a function of time during polymerization with $\alpha-\mathrm{ZrP} \cdot \mathrm{Im}$ $(\Delta), \alpha-Z r P \cdot 2 \mathrm{MIm}(\square), \alpha-\mathrm{ZrP} \cdot 2 \mathrm{E} 4 \mathrm{MIm}(\bigcirc), \alpha-\mathrm{ZrP} \cdot \mathrm{DABCO}(\square)$ [11], $\alpha-\mathrm{ZrP} \cdot \mathrm{DBU}(\Delta)$ [11], HX-3088 $(\diamond)$, and HX-3722 (•) at $40{ }^{\circ} \mathrm{C}$.

This reaction system of GPE-MHHPA has an advantage for characterization of the resulting imidazoles-intercalated $\alpha$-ZrPs after the reaction. Thus, the resulting ones can be easily isolated by simply washing the products with an organic solvent. After the reaction of GPE with MHHPA in the presence of imidazoles-intercalated $\alpha$-ZrPs at $140^{\circ} \mathrm{C}$ for $2 \mathrm{~h}$ or $1 \mathrm{~h}$, the resulting imidazoles-intercalated $\alpha$-ZrPs (hereafter abbreviated as $\alpha$-ZrP·Im-RXN, $\alpha-Z r P \cdot 2 \mathrm{MIm}-\mathrm{RXN}$, and $\alpha-\mathrm{ZrP} \cdot 2 \mathrm{E} 4 \mathrm{MIm}-\mathrm{RXN}$ ) were isolated and characterized by XRD, NMR, and elemental analyses. Basal distances, chemical shifts of the main signals, and elemental analyses are listed in Table 1.

Table 1. Elemental analysis, basal distance, and MAS NMR chemical shift of imidazoles-intercalated $\alpha-\mathrm{ZrP}(\alpha-\mathrm{ZrP} \cdot \mathrm{Ims})$ and those of imidazoles-intercalated $\alpha-\mathrm{ZrP}(\alpha-\mathrm{ZrP} \cdot \mathrm{Ims}-\mathrm{RXN})$ after the reaction at $140{ }^{\circ} \mathrm{C}$.

\begin{tabular}{|c|c|c|c|c|c|c|}
\hline$\alpha-Z r P \cdot I m s$ & $\mathrm{C}(\%)$ & H (\%) & N (\%) & $d(\AA)$ & ${ }^{31} \mathbf{P}(\delta)$ & ${ }^{13} \mathrm{C}(\delta)$ \\
\hline$\alpha-\mathrm{ZrP} \cdot \operatorname{Im}$ & 7.87 & 2.09 & 5.61 & 10.7 & $\begin{array}{c}-15.9,-16.8 \\
-23.7\end{array}$ & $134.2,120.2$ \\
\hline$\alpha-\mathrm{ZrP} \cdot \operatorname{Im}-\mathrm{RXN}$ & 15.02 & 2.53 & 3.84 & 24.4 & $-16.1,-22.2$ & $\begin{array}{c}158.8,134.1,132.4,129.8 \\
119.8,116.7,67.9\end{array}$ \\
\hline$\alpha-\mathrm{ZrP} \cdot 2 \mathrm{MIm}$ & 12.08 & 2.66 & 7.00 & 12.1 & $\begin{array}{c}-21.0,-22.2 \\
-23.4\end{array}$ & $\begin{array}{c}143.8,142.4,122.0,120.2 \\
117.3,13.4,10.3\end{array}$ \\
\hline$\alpha-Z r P \cdot 2 M I m-R X N$ & 17.85 & 2.87 & 3.60 & 24.4 & -21.5 & $\begin{array}{c}158.9,145.3,141.0,129.2 \\
120.3,117.6,114.9,68.9 \\
12.6,11.4,10.2\end{array}$ \\
\hline$\alpha-\mathrm{ZrP} \cdot 2 \mathrm{E} 4 \mathrm{MIm}$ & 12.85 & 2.68 & 4.78 & 12.9 & $-16.1,-22.2$ & $\begin{array}{c}147.3,129.4,116.5,18.9 \\
11.4,8.8\end{array}$ \\
\hline$\alpha-\mathrm{ZrP} \cdot 2 \mathrm{E} 4 \mathrm{MIm}-\mathrm{RXN}$ & 22.75 & 2.94 & 2.75 & 24.1 & $-14.8,-20.6$ & $\begin{array}{c}159.1,147.7,128.5,118.1 \\
69.2,19.1,10.1\end{array}$ \\
\hline
\end{tabular}

The XRD patterns of pristine $\alpha-\mathrm{ZrP}$ is shown in Figure 5a. The peak corresponding to the basal distance of $7.6 \AA$ was expanded with the intercalation of imidazoles. The XRD patterns of $\alpha-\mathrm{ZrP} \cdot \mathrm{Im}$ and $\alpha-\mathrm{ZrP} \cdot \mathrm{Im}-\mathrm{RXN}$ are shown in Figure $5 \mathrm{~b}$,c. In addition to the peak corresponding to $10.7 \AA$ of $\alpha$-ZrP.Im, a small broad peak was observed at $24.4 \AA(2 \theta=3.6)$ in that of $\alpha$-ZrP.Im-RXN. In the ${ }^{31} \mathrm{P}$ MAS NMR spectra of $\alpha$-ZrP·Im and $\alpha$-ZrP·Im-RXN, the main signals at $-15.9,-16.8$, and 
$-23.7 \mathrm{ppm}$ shifted to -16.1 and $-22.0 \mathrm{ppm}$ as shown in Figure 6a,b. In the ${ }^{31} \mathrm{P}$ MAS NMR spectra of intercalation compounds of $\alpha$-ZrP.Im and $\alpha$-ZrP.2E4MIm, the peak of deprotonated phosphate groups were observed at $\delta$ value of -15.9 and -16.8 for $\alpha$-ZrP.Im and -16.1 for $\alpha$-ZrP.2E4MIm. The single peak of pristine $\alpha-Z r P$ is shown at a $\delta$ value of -20.1 [10]. The peak $\delta$ value of higher than that of -20.1 for $\alpha$-ZrP.2MIm doesn't observed. That might show the separation of 2MIm from phosphate group. In the ${ }^{13} \mathrm{C}$ CPMAS NMR spectra presented in Figure $6 \mathrm{~d}, \mathrm{e}$, the aromatic carbons associated with the GPE at $\delta=158.8,132.4,129.8$, and $116.7 \mathrm{ppm}$ and the structural main chain methylene groups at $\delta=67.9$ were observed. However, the carbonyl carbon of the resulting poly(GPE-co-MHHPA) at $\delta=172.9$ in Figure 6e was not observed in that of $\alpha$-ZrP.Im-RXN. The resulting products were derived from GPE. A possible phosphate ester formed by $\mathrm{PO}_{4}$ of $\alpha-\mathrm{ZrP}$ with GPE may be denied by the chemical shifts in the ${ }^{13} \mathrm{C} C \mathrm{CP}$ MAS NMR spectra. Phosphate esters produced by the reaction of $\alpha$-ZrP and 1,2-epoxydodecane, the carbons generated from epoxide were observed at $\delta=61.6$ and 71.2 for $\beta$-cleavage and $\delta=79.6$ and 71.2 for $\alpha$-cleavage in 13C CP MAS NMR spectra [25]. Epoxy-ring opening products, such as the homo-oligomer of GPE, exist in the interlayer. In the following cases, the epoxy-ring opening products are formed in the interlayer.

In the XRD patterns of $\alpha$-ZrP.2MIm and $\alpha$-ZrP.2MIm-RXN (shown in Figure $5 \mathrm{~d}$,e), the basal distances were shortened from 12.1 to $11.3 \AA$ and a broad peak was observed at $24.4 \AA(2 \theta=3.6)$. In the ${ }^{31} \mathrm{P}$ MAS NMR spectra, the main signals at $-21.0,-22.2$, and $-23.4 \mathrm{ppm}$ shifted to $-21.5 \mathrm{ppm}$. Similarly, the aromatic carbons and methylene groups derived from GPE were observed in the ${ }^{13} \mathrm{C}$ CPMAS NMR spectra.
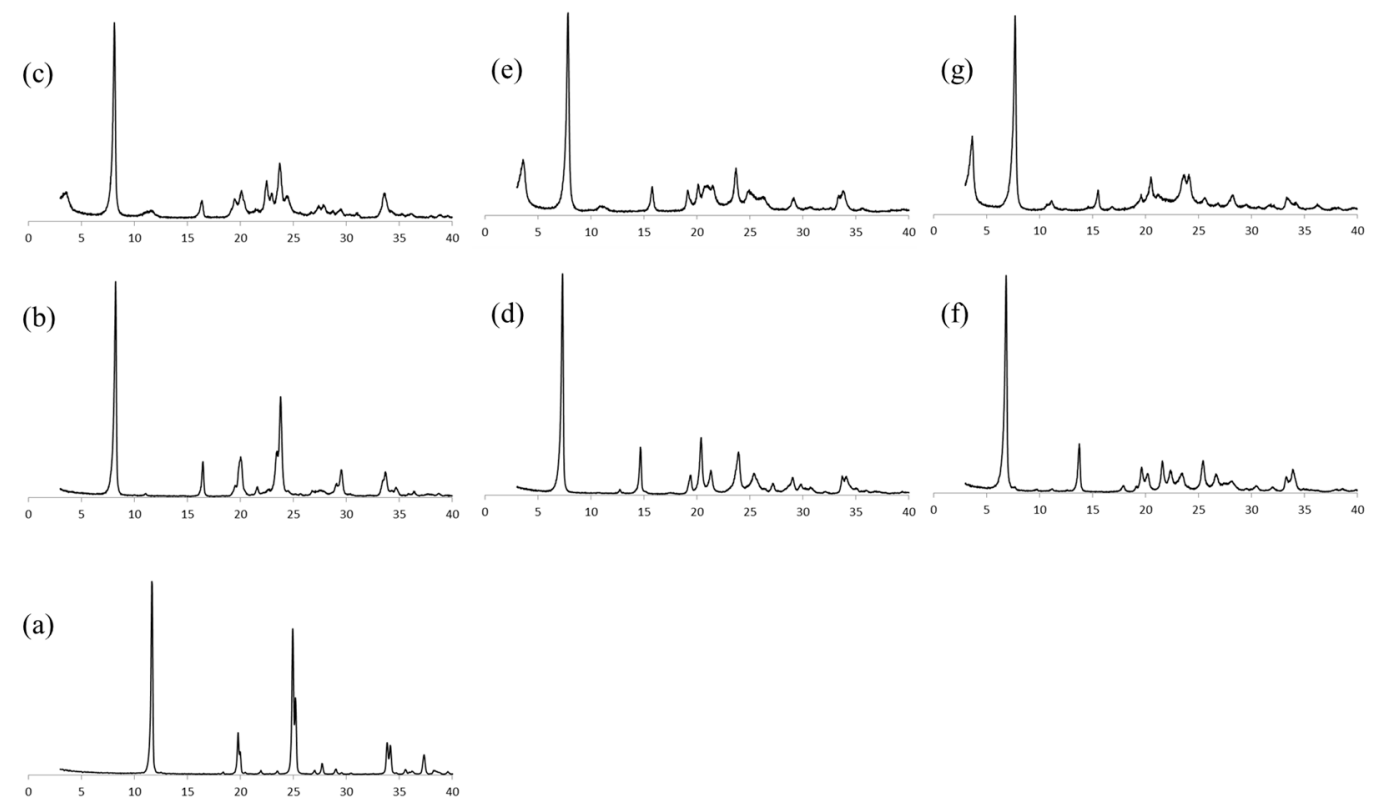

Figure 5. XRD patterns of (a) pristine $\alpha$-ZrP, (b) $\alpha$-ZrP·Im, (c) $\alpha-\mathrm{ZrP} \cdot \operatorname{Im}-\mathrm{RXN}$, (d) $\alpha$-ZrP.2MIm, (e) $\alpha$-ZrP·2MIm-RXN, (f) $\alpha$-ZrP·2E4MIm, and (g) $\alpha-Z r P \cdot 2 E 4 M I m-R X N$.

In the case of $\alpha$-ZrP.2E4MIm, similar to $\alpha$-ZrP.2MIm, the basal distances were shortened from 12.9 to $11.5 \AA$ and a broad peak was observed at $24.1 \AA(2 \theta=3.7)$. In the ${ }^{31}$ P MAS NMR spectrum, the main signals at -16.1 , and $-22.2 \mathrm{ppm}$ shifted to -14.8 and $-20.6 \mathrm{ppm}$. In the ${ }^{13} \mathrm{C}$ CPMAS NMR spectrum, the aromatic carbons and methylene groups derived from GPE were similarly observed.

In any case, with the expansion of the basal distances, an increase in $C$ content was recognized. Moreover, the ${ }^{13} \mathrm{C}$ CPMAS NMR suggested the presence of substances derived from GPE in the interlayer. Based on the elemental analyses, the compositions were calculated to give GPE $/ \mathrm{Im}=0.7$, $\mathrm{Zr}\left(\mathrm{HPO}_{4}\right)_{2}\left(\mathrm{C}_{3} \mathrm{H}_{4} \mathrm{~N}_{2}\right)_{0.51} \cdot(\mathrm{GPE})_{0.34}$ for $\alpha$-ZrP·Im-RXN, GPE/2MIm $=0.8, \mathrm{Zr}\left(\mathrm{HPO}_{4}\right)_{2}\left(\mathrm{C}_{4} \mathrm{H}_{6} \mathrm{~N}_{2}\right)_{0.50} \cdot(\mathrm{GPE})_{0.42}$ 
for $\alpha$-ZrP·2MIm-RXN, and GPE/2E4MIm $=1.5, \mathrm{Zr}\left(\mathrm{HPO}_{4}\right)_{2}\left(\mathrm{C}_{6} \mathrm{H}_{10} \mathrm{~N}_{2}\right)_{0.41} \cdot(\mathrm{GPE})_{0.61}$ for $\alpha-\mathrm{ZrP} \cdot 2 \mathrm{E} 4 \mathrm{MIm}-$ RXN. Thus, $35 \%$ of imidazole, $48 \%$ of 2 -methylimidazole, or $37 \%$ of 2 -ethyl-4-methylimidazole was deintercalated in each case. These deintercalated imidazoles initiated the copolymerization of GPE and MHHPA. Since there was not a substantial difference among the catalytic activities of imidazole, 2-methylimidazole, and 2-ethyl- 4-methyl imidazole in this reaction, the amount of deintercalated imidazoles must affect reactivity (as shown in Figure 3) and thermal stability (as shown in Figure 4). In fact, the order of thermal instability and that of reactivity were $\alpha$-ZrP.2MIm $>\alpha$-ZrP.2E4MIm $>$ $\alpha-\mathrm{ZrP} \cdot \mathrm{Im}$, which corresponded to the amount of the deintercalated imidazoles.

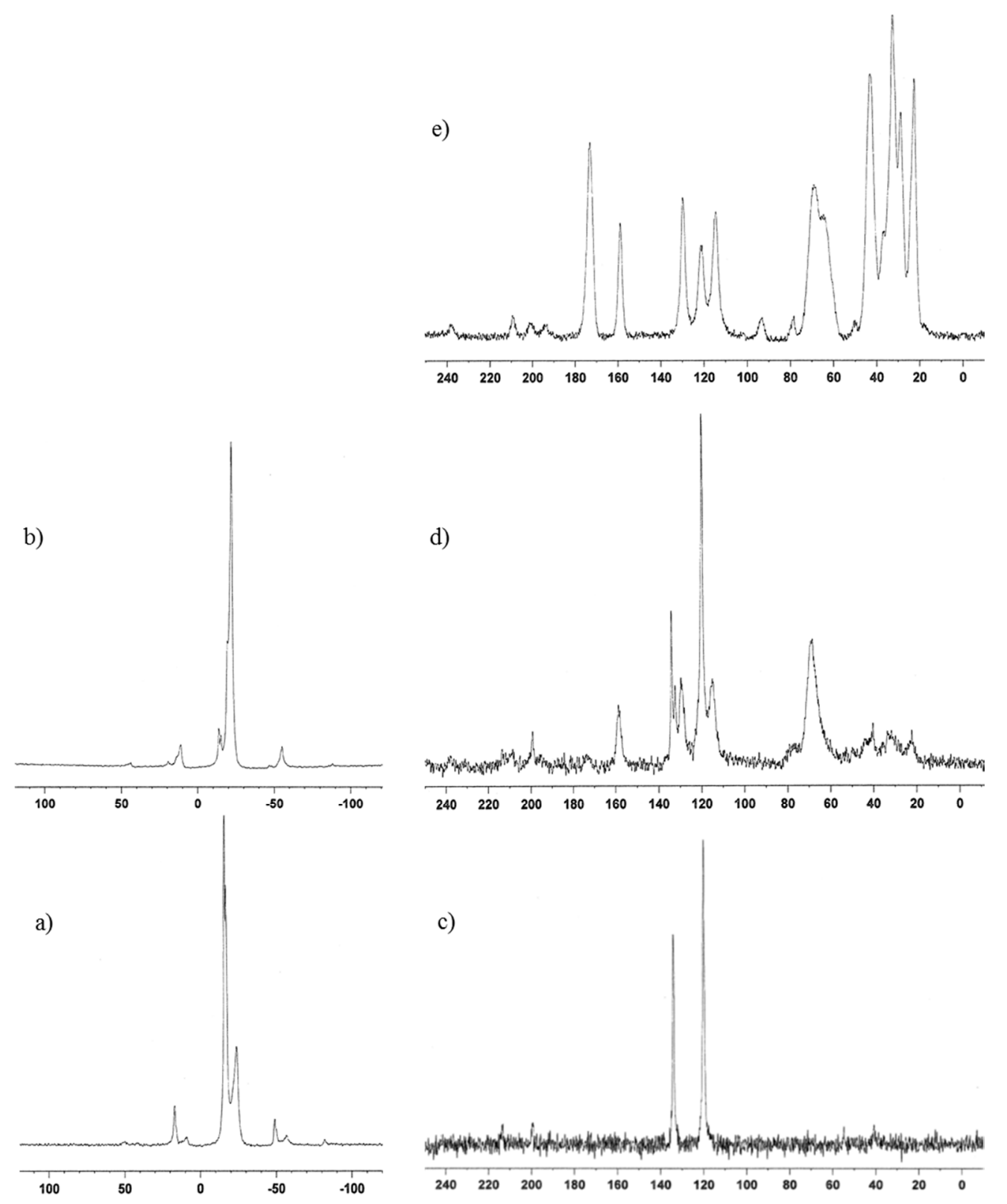

Figure 6. ${ }^{31} \mathrm{P}$ NMR spectra of (a) $\alpha$-ZrP.Im and (b) $\alpha$-ZrP.Im-RXN, and ${ }^{13} \mathrm{C} N M R$ spectra of (c) $\alpha$-ZrP.Im, (d) $\alpha$-ZrP·Im-RXN, and (e) poly(GPE-co-MHHPA).

In these cases, while the imidazoles were deintercalated, the intercalation of GPE and successive reactions occurred. In the preceding paper, the interlayer polymerization of GPE- MHHPA with $\alpha$-ZrP.DBU; in contrast, the lack of interlayer polymerization with $\alpha$-ZrP.DABCO were observed [11]. 
The compositions after the polymerization of $\alpha$-ZrP.DBU and $\alpha$-ZrP.DABCO were calculated based on the contents of $\mathrm{N} \%$ and $\mathrm{H} \%$ of the elemental analyses. The results are as follows: $\alpha$-ZrP.DBU (basal distance: 20.0A): $\mathrm{Zr}\left(\mathrm{HPO}_{4}\right)_{2}\left(\mathrm{C}_{9} \mathrm{H}_{16} \mathrm{~N}_{2}\right)_{0.83} \cdot 2.8 \mathrm{H}_{2} \mathrm{O}, \alpha-\mathrm{ZrP} \cdot \mathrm{DBU}-\mathrm{RXN}$ : GPE-MHHPA/DBU $=3.7, \mathrm{Zr}\left(\mathrm{HPO}_{4}\right)_{2}\left(\mathrm{C}_{9} \mathrm{H}_{16} \mathrm{~N}_{2}\right)_{0.24} \cdot(\mathrm{GPE}-\mathrm{MHHPA})_{0.89}, \alpha-\mathrm{ZrP} \cdot \mathrm{DABCO}$ (basal distance: 16.1A): $\mathrm{Zr}\left(\mathrm{HPO}_{4}\right)_{2}\left(\mathrm{C}_{6} \mathrm{H}_{12} \mathrm{~N}_{2}\right)_{0.69} \cdot 1.5 \mathrm{H}_{2} \mathrm{O}, \alpha-\mathrm{ZrP} \cdot \mathrm{DABCO}-\mathrm{RXN}$ : $\mathrm{Zr}\left(\mathrm{HPO}_{4}\right)_{2}\left(\mathrm{C}_{6} \mathrm{H}_{12} \mathrm{~N}_{2}\right)_{0.63} \cdot(\mathrm{GPE}-\mathrm{MHHPA})_{0.03}$. Thus, $72 \%$ of DBU and $9 \%$ of DABCO were deintercalated in these cases; at the same time, in TG-DTA data of imidazoles-, DBU-, and DABCO-intercalated ZrPs, these amines appeared not to be deintercalated up to $140{ }^{\circ} \mathrm{C}$, and sufficient deintercalation of the amines in the reactants took place at $140{ }^{\circ} \mathrm{C}$. Accordingly, when the intercalated amine was sufficiently deintercalated to afford enough space for GPE, the interlayer reaction occurred to expand the basal distance.

In our system, control of the deintercalation of amines was an important factor in the design of the latent thermal initiator. In addition to the $\mathrm{p} K_{\mathrm{a}}$ of the amines, the basal distances related to the molecular shape and size of the amines, the shape and size of $\alpha$-zirconium phosphate, the structural design of the intercalation compounds, and the equilibrium of the reactants should be thermodynamically considered.

\section{Experimental Section}

\subsection{Materials}

$\mathrm{Zr}\left(\mathrm{HPO}_{4}\right)_{2} \cdot \mathrm{H}_{2} \mathrm{O}$ (CZP-100) was purchased from Daiichi Kigenso Kagaku Kogyo Co., Ltd. (Osaka, Japan); GPE from Aldrich Chemical Co., Inc. (Tokyo, Japan); imidazole, 2-methylimidazole, 2-ethyl-4-methylimidazole, and MHHPA from Tokyo Chemical Industries, Co., Ltd. (Tokyo, Japan); HX-3088 and HX-3722 from Asahi Kasei Co. Ltd. (Tokyo, Japan). Solvents were used as received without further purification.

\subsection{Measurements}

X-ray diffraction (XRD) patterns were obtained using a Rigaku RINT2200 (Rigaku CO., Ltd., Tokyo, Japan) with $\mathrm{Cu} \mathrm{K} \alpha$ radiation over a scan range of $3-40^{\circ}$ at a rate of $2^{\circ} \mathrm{min}^{-1}$. NMR spectra in solution were recorded on a Varian Unity-300 spectrometer (Varian Co., Inc., Palo Alto, CA, USA) using tetramethylsilane (TMS) as an internal standard. The contents of imidazoles and water in the intercalation compounds of $\alpha$-ZrP were measured using a Yanaco CHN Corder MT-5 (Yanako Co., Ltd., Kyoto, Japan). ${ }^{31} \mathrm{P}$ MAS and ${ }^{13} \mathrm{C}$ CPMAS NMR spectra were recorded on a Bruker AVANCEIII600WB NMR spectrometer (Bruker Co. Inc., Billerica, MA, USA). Thermogravimetric analyses (TGA) were carried out with a Shimadzu DTG-60 (Shimadzu Co., Ltd., Kyoto, Japan) at a heating rate of $10^{\circ} \mathrm{C} / \mathrm{min}$ under nitrogen. Gel permeation chromatographic analyses (GPC) were carried out on a Shodex GPC-101 (LF804*3 and KF-800RF*3, THF as eluent) (Showa Denko Co. Ltd., Tokyo, Japan) using polystyrene standards.

\subsection{Preparation of Imidazole-Intercalated $\alpha$-ZrP $(\alpha-Z r P \cdot I m)$}

The intercalation of imidazole into the layers of $\mathrm{Zr}\left(\mathrm{HPO}_{4}\right)_{2} \cdot \mathrm{H}_{2} \mathrm{O}(\alpha-\mathrm{ZrP})$ was carried out using a previously reported method [16]. $\alpha-\mathrm{ZrP}(10 \mathrm{~g})$ was added to $142 \mathrm{~mL}$ of a $0.7 \mathrm{~mol} \mathrm{dm}{ }^{-3}$ imidazole aqueous solution. The reaction mixture was then allowed to stand at $40^{\circ} \mathrm{C}$ for $24 \mathrm{~h}$, before the product was collected by centrifugation and washed with water several times. The resulting residue was dried under vacuum. The intercalation of 2-methylimidazole (2MIm) and 2-ethyl-4-methylimidazole (2E4MIm) were carried out by the same procedure for the preparation of $\alpha-\mathrm{ZrP} \cdot \mathrm{Im}$.

$$
\alpha-\operatorname{ZrP}(7.6 \AA)+\underset{\operatorname{Im}}{2 \mathrm{MIm}} \longrightarrow \begin{gathered}
\alpha-\mathrm{ZrP} \cdot \operatorname{Im}(10.7 \AA) \\
2 \mathrm{E} 4 \mathrm{MIm}
\end{gathered} \quad \begin{gathered}
\alpha \mathrm{ZrP} \cdot 2 \mathrm{MIm}(12.1 \AA) \\
\alpha-\mathrm{ZrP} \cdot 2 \mathrm{E} 4 \mathrm{MIm}(12.9 \AA)
\end{gathered}
$$




\subsection{Typical Polymerization Procedure}

A mixture of GPE (151 mg, $1.0 \mathrm{mmol})$, MHHPA (172 mg, $1.0 \mathrm{mmol})$, and intercalation compound of imidazole with $\alpha$-ZrP $(\alpha-\mathrm{ZrP} \cdot \mathrm{Im})(11.0 \mathrm{mg}, 0.031 \mathrm{mmol}$, content of imidazole: $0.024 \mathrm{mmol})$ was heated at $140{ }^{\circ} \mathrm{C}$ for $1 \mathrm{~h}$. A small aliquot of the reaction mixture was dissolved in $\mathrm{CDCl}_{3}$, and its ${ }^{1} \mathrm{H}-\mathrm{NMR}$ spectra was acquired to determine the extent of the conversion of GPE and MHHPA. In the case of $40{ }^{\circ} \mathrm{C}$, the small aliquot of sample was collected every determined time. The polymerization with intercalation compound of 2-methylimidazole with $\alpha-\mathrm{ZrP}(\alpha-\mathrm{ZrP} \cdot 2 \mathrm{MIm})(11.7 \mathrm{mg}, 0.031 \mathrm{mmol}$, content of 2-methylimidazole: $0.029 \mathrm{mmol}$ ) and intercalation compound of 2-ethyl-4-methylimidazole with $\alpha$-ZrP ( $\alpha$-ZrP.2E4MIm) (11.2 mg, $0.031 \mathrm{mmol}$, content of 2-ethyl-4-methylimidazole: $0.020 \mathrm{mmol})$ were carried out by the same procedure for the preparation of poly(GPE-co-MHHPA) with $\alpha$-ZrP.Im. Commercial agents of the encapsulation of imidazoles, ca. $10 \mathrm{mg}$ of HX-3088 and HX-3722 were used by the same procedure.

\subsection{Polymerization Procedure for Preparation of Poly(GPE-co-MHHPA) with $\alpha-Z r P \cdot I m$}

A mixture of GPE (7.51 g, $50.0 \mathrm{mmol})$, MHHPA (8.41 g, $50.0 \mathrm{mmol})$, and $\alpha$-ZrP.Im (535 mg, $1.50 \mathrm{mmol}$, content of imidazole: $1.17 \mathrm{mmol}$ ) was heated at $140{ }^{\circ} \mathrm{C}$ for $2 \mathrm{~h}$. After the reaction, tetrahydrofurane (THF) was added to the mixture and filtered off, and the residue, $\alpha-\mathrm{ZrP} \cdot \mathrm{Im}-\mathrm{RXN}$, was rinsed to wash the polymer. The obtained $\alpha$-ZrP.Im-RXN was dried under vacuum and served to measure the XRD analysis. The obtained polymer was isolated by the precipitation with methanol and dried under vacuum with 50\% yield. The copolymer was identified as poly(GPE-co-MHHPA) by ${ }^{1} \mathrm{H}-\mathrm{NMR}$ spectra. The number-average molecular weight $(\mathrm{Mn})$ and the molecular weight distribution $(\mathrm{Mw} / \mathrm{Mn})$ were found to be 1990 and 1.4, respectively (GPC, calibrated by polystyrene standards). The polymerization with $\alpha$-ZrP.2MIm and $\alpha$-ZrP.2E4MIm was carried out at $140^{\circ} \mathrm{C}$ for $1 \mathrm{~h}$ to obtain the corresponding poly(GPE-co-MHHPA). $\alpha$-ZrP.2MIm: $M n=2080, M w / M n=1.4, \alpha$-ZrP.2E4MIm: $M n=3120, M w / M n=1.3$.

\section{Conclusions}

The activities of $\alpha$-ZrP·Im, $\alpha$-ZrP·2MIm, and $\alpha$-ZrP·2E4MIm in the copolymerization of GPE and MHHPA as latent thermal initiators were examined in this study. Compared with the commercially available thermal latent initiators HX-3088 and HX-3722, $\alpha$-ZrP·Im, $\alpha$-ZrP·2MIm, and $\alpha$-ZrP.2E4MIm were more thermally stable at $40{ }^{\circ} \mathrm{C}$ and effectively initiated the reaction at $140{ }^{\circ} \mathrm{C}$. Imidazoles intercalated $\alpha-\mathrm{ZrP}$ were stable under $40{ }^{\circ} \mathrm{C}$ because of the fixation of acid-base interaction and physical protection by the interlayer of $\alpha-\mathrm{ZrP}$. The intercalation compounds of the order of thermal instability and that of reactivity were $\alpha-\mathrm{ZrP} \cdot 2 \mathrm{MIm}>\alpha-\mathrm{ZrP} \cdot 2 \mathrm{E} 4 \mathrm{MIm}>\alpha-\mathrm{ZrP} \cdot \mathrm{Im}$, which corresponded to the amount of the deintercalated imidazoles. Thus, control of the amount of the deintercalated imidazoles from $\alpha$-ZrP.Im, $\alpha$-ZrP.2MIm, and $\alpha-\mathrm{ZrP} \cdot 2 \mathrm{E} 4 \mathrm{MIm}$ is an important factor in thermal latent initiators. We are studying further to control the amount of deintercalation and the relation of molecular shape, size, and properties.

Supplementary Materials: The following are available online at www.mdpi.com/2073-4344/7/6/172/s1, Figure S1, ${ }^{31} \mathrm{P}$ NMR spectra of (a) $\alpha$-ZrP.2MIm; (b) $\alpha$-ZrP.2MIm-RXN and ${ }^{13} \mathrm{C}$ NMR spectra of (c) $\alpha$-ZrP.2MIm; (d) $\alpha$-ZrP.2MIm-RXN; and (e) poly[GPE-co-MHHPA]. Figure S2, ${ }^{31} \mathrm{P}$ NMR spectra of (a) $\alpha$-ZrP.2E4MIm; (b) $\alpha$-ZrP.2E4MIm-RXN and ${ }^{13}$ C NMR spectra of (c) $\alpha$-ZrP.2E4MIm; (d) $\alpha$-ZrP.2E4MIm-RXN; and (e) poly[GPE-co-MHHPA].

Acknowledgments: This work was performed under the Cooperative Research Program of Network Joint Research Center for Materials and Devices. We also thank M. Shizuma and S. Kawano of Osaka Research Institute of Industrial Science and Technology for GPC analyses.

Author Contributions: Osamu Shimomura and Shunro Yamaguchi conceived, designed and wrote the article; Kensuke Tokizane and Takatoshi Nishisako performed the experiments; Junko Ichihara, Manabu Kirino, Atsushi Ohtaka and Ryôki Nomura contributed to a helpful discussion.

Conflicts of Interest: The authors declare no conflict of interest. 


\section{References}

1. Kikkawa, A.; Takata, T.; Endo, T. Effect of alkyl substituents on initiator activity in cationic polymerization of styrene with p-methoxybenzyldialkylsulfonium salts as initiators. J. Polym. Sci. Part A Polym. Chem. 1991, 29, 1089-1095. [CrossRef]

2. Shimomura, O.; Tomita, I.; Endo, T. Application of S-alkylsulfonium salts of aromatic sulfides as new thermal latent cationic initiators. J. Polym. Sci. Part A Polym. Chem. 2000, 38, 18-27. [CrossRef]

3. Crivello, J.V. Design of photoacid generating systems. J. Photopolym. Sci. Technol. 2009, 22, 575-582. [CrossRef]

4. Hacker, N.P.; Welsh, K.M. Photochemistry of triphenylsulfonium salts in poly[4-[(tert-butoxycarbonyl)oxy]styrene]: Evidence for a dual photoinitiation process. Macromolecules 1991, 24, 2137-2139. [CrossRef]

5. Toneri, T.; Sanda, F.; Endo, T. Polymerization of epoxide with a fluorenyltriphenylphosphonium salt as a photo-latent initiator. J. Photopolym. Sci. Technol. 1999, 12, 159-164. [CrossRef]

6. Kim, M.S.; Lee, K.W.; Endo, T.; Lee, S.B. Benzylpyrazinium Salts as Thermally Latent Initiators in the Polymerization of Glycidyl Phenyl Ether: Substituent Effect on the Initiator Activity and Mechanistic Aspects. Macromolecules 2004, 37, 5830-5834. [CrossRef]

7. Naumann, S.; Speiser, M.; Schowner, R.; Giebel, E.; Buchmeiser, M.R. Air Stable and Latent Single-Component Curing of Epoxy/Anhydride Resins Catalyzed by Thermally Liberated N-Heterocyclic Carbenes. Macromolecules 2014, 47, 4548-4556. [CrossRef]

8. Kirino, M.; Tomita, I. Aminimides Derived from Benzoylformic Acid Esters as Thermally Latent Base Catalysts. Macromolecules 2010, 43, 8821-8827. [CrossRef]

9. Sudo, A.; Yamashita, H.; Endo, T. Ring-opening polymerization of 1,3-benzoxazines by p-toluenesulfonates as thermally latent initiators. J. Polym. Sci. Part A Polym. Chem. 2011, 49, 3631-3636. [CrossRef]

10. Shimomura, O.; Maeno, K.; Ohtaka, A.; Yamaguchi, S.; Ichihara, J.; Sakamoto, K.; Nomura, R. Alkylaminesintercalated $\alpha$-zirconium phosphate as latent thermal anionic initiators. J. Polym. Sci. Part A Polym. Chem. 2014, 52, 1854-1861. [CrossRef]

11. Shimomura, O.; Nishisako, T.; Yamaguchi, S.; Ichihara, J.; Kirino, M.; Ohtaka, A.; Nomura, R. DABCO- and DBU-intercalated $\alpha$-zirconium phosphate as latent thermal catalysts in the copolymerization of glycidyl phenyl ether (GPE) and hexahydro-4-methylphthalic anhydride (MHHPA). J. Mol. Catal. A Chem. 2016, 411, 230-238. [CrossRef]

12. Ricciardi, F.; Romanchick, W.A.; Joullie, M.M. Mechanism of imidazole catalysis in the curing of epoxy resins. J. Polym. Sci. Polym. Chem. Ed. 1983, 21, 1475-1490. [CrossRef]

13. Farkas, A.; Strohm, P.F. Imidazole catalysis in the curing of epoxy resins. J. Appl. Polym. Sci. 1968, 12, $159-168$. [CrossRef]

14. Ricciardi, F.; Romanchick, W.A.; Joullie, M.M. 1,3-Dialkylimidazolium salts as latent catalysts in the curing of epoxy resins. J. Polym. Sci. Polym. Lett. Ed. 1983, 21, 633-638. [CrossRef]

15. Shin, M.J.; Shin, Y.J.; Hwang, S.W.; Shin, J.S. Microencapsulation of imidazole curing agent by solvent evaporation method using W/O/W emulsion. J. Appl. Polym. Sci. 2013, 129, 1036-1044. [CrossRef]

16. Kudo, K.; Fuse, S.; Furutani, M.; Arimitsu, K. Imidazole-type thermal latent curing agents with high miscibility for one-component epoxy thermosetting resins. J. Polym. Sci. Part A Polym. Chem. 2016, 54, 2680-2688. [CrossRef]

17. Oono, Y.; Kato, H. Storage-Stable Thermosetting Epoxy Resin Compositions Containing Latent Curing Accelerators. 1993-195102, 07025989, 19930712, 1995.

18. Oono, Y.; Iinuma, T.; Kato, H. Thermosetting Epoxy Resin Compositions Containing Latent Crosslinking Catalysts. 1993-26218, 06073162, 19930120, 1994.

19. Boo, W.J.; Sun, L.; Liu, J.; Clearfield, A.; Sue, H.-J. Effective Intercalation and Exfoliation of Nanoplatelets in Epoxy via Creation of Porous Pathways. J. Phys. Chem. C 2007, 111, 10377-10381. [CrossRef]

20. White, K.L.; Wong, M.; Li, P.; Miyamoto, M.; Higaki, Y.; Takahara, A.; Sue, H.J. Interlayer structure and self-healing in suspensions of brush-stabilized nanoplatelets with smectic order. Soft Matter 2015, 11, 954-971. [CrossRef] [PubMed]

21. Li, P.; White, K.L.; Lin, C.H.; Kim, D.; Muliana, A.; Krishnamoorti, R.; Nishimura, R.; Sue, H.J. Mechanical reinforcement of epoxy with self-assembled synthetic clay in smectic order. ACS Appl. Mater. Interfaces 2014, 6, 10188-10195. [CrossRef] [PubMed] 
22. Armarego, W.; Chai, C. purification of organic chemicalsIn Purification of Laboratory Chemicals, 6th ed.; Elsevier: Oxford, UK, 2009; Chapter 4.

23. Kamon, T.; Saito, K.; Miwa, Y.; Saeki, K. The curing of epoxy resin (V): The curing of epoxy resins with imidazoles, and the structure and the properties of the cured resins. Shikizai 1976, 49, 82-89. [CrossRef]

24. MacLachlan, D.J.; Morgan, K.R. Phosphorus-31 solid-state NMR studies of the structure of amine-intercalated $\alpha$-zirconium phosphate. 2 . Titration of $\alpha$-zirconium phosphate with n-propylamine and n-butylamine. J. Phys. Chem. 1992, 96, 3458-3464. [CrossRef]

25. Casciola, M.; Capitani, D.; Donnadio, A.; Munari, G.; Pica, M. Organically Modified Zirconium Phosphate by Reaction with 1,2-Epoxydodecane as Host Material for Polymer Intercalation: Synthesis and Physicochemical Characterization. Inorg. Chem. 2010, 49, 3329-3336. [CrossRef] [PubMed]

(C) 2017 by the authors. Licensee MDPI, Basel, Switzerland. This article is an open access article distributed under the terms and conditions of the Creative Commons Attribution (CC BY) license (http://creativecommons.org/licenses/by/4.0/). 